\title{
Germ Cell Differentiations During Spermatogenensis and Taxonomic Values of Mature Sperm Morphology of Pinctada martensii (Bivalvia, Pteriomorphia, Pteriidae)
}

\author{
Jin Hee Kim', Sung Han Kim², and Ki-Young Lee ${ }^{3}$ \\ ${ }^{1}$ Marine Eco-Technology Institute, Busan 608-830, Korea \\ ${ }^{2}$ Department of Aquaculture and Aquatic Sciences, Kunsan National University, Gunsan 573-701, Korea \\ ${ }^{3}$ Department of Marine Biotechnology, Kunsan National University, Gunsan 573-701, Korea
}

\begin{abstract}
The ultrastructural characteristics of germ cells during spermatogenesis and mature sperm morphology in male Pinctada martensii were investigated by transmission electron microscope observation. The morphologies of the sperm nucleus and the acrosome of this species are the oval shape and cone shape, respectively. Spermatozoa are approximately 47-50 $\mu \mathrm{m}$ in length including a sperm nucleus (about $1.24 \mu \mathrm{m}$ in length), an acrosome (about $0.60 \mu \mathrm{m}$ in length), and tail flagellum (about $45-47 \mu \mathrm{m}$ ). The axoneme of the sperm tail shows a 9+2 structure. In $P$. martensii in Pteriidae, a special substructure showing a thick and wide triangular shape which is composed of electron-dense opaque material (occupied about $50 \%$ of all, the upper part of the acrosomal vesicle), appeared in the upper region (part) of the acrosomal vesicle, while the lower region (part) of the acrosomal vesicle is composed of electron-lucent material. Thus, this special structure, which exist in the upper part of the acrosomal vesicle in $P$. martensii, is somewhat different from those of other subacrosomal vesicle in other families in subacrosomal vesicles. Therefore, we assume that the existence of a special substructure showing a thick and wide triangular shape in the acrosomal vesicle of the spermatozoon can be used as a key characteristic for identification of $P$. martensii or other species in Pteriidae in subclass Pteriomorphia. The number of mitochondria in the midpiece of the sperm of this species are five (exceptionally sometimes four), as one of common characteristics appear the same number of mitochondria in the same families of superfamilyies. This species in Pteriidae does not contain the axial rod and satellite fibres which appear in the species in Ostreidae in subclass Pteriomorphia. These characteristics can be used for the taxonomic analysis of the family or superfamily levels as a systematic key or tools.
\end{abstract}

Key words: Pinctada martensii, spermatogenesis, germ cell, mature sperm morphology

\section{INTRODUCTION}

Aside from their natural resource significance, Pinctada martensii in family Pteriidae comprise one of the more taxonomically important group of bivalve molluscs. Utrastructural studies have been described the spermatogenesis and spermatozoa of a number of

Received September 21, 2011 ; Accepted September 28, 2011

Corresponding author: Jin Hee Kim

Tel: +82 (70) 8630-7109 e-mail: jiny90000@hanmail.net $1225-3480 / 24403$ bivalve species using electron microscopy (Longo and Dornfelds, 1967; Longo and Anderson, 1969; Popham, 1979; Bernard and Hodgson, 1985; Hodgson and Bernard, 1986; Healy, 1989; Eckelbarger et al., 1990; Eckelbarger and Davis, 1996; Gaulejac et al., 1995; Chung and Ryou, 2000; Chung et al., 2007, 2010).

It is well-known that the ultrastructure of the spermatozoon in the bivalves might be related to the systematics of bivalves (Popham et al., 1974). For that reason, sperm ultrastructure has long been viewed as a tool in assessing phylogenetic relationships in the metazoa through the use of spermiocladistic analysis (Franzén, 1970). 
To date, comprehensive studies on spermatogenesis of bivalves in Korea have been restricted to several species in the families Mactridae (Chung and Ryou, 2001), Mytilidae (Kim, 2001, Kim et al., 2010b), Veneridae (Cnung et al., 2001; Kim and Kim, 2011), Pectinidae (Kim, 2001), Ostreidae (Kim et al., 2010a) in the subclass Pteriomorphia.

Within the bivalves there is little variation in the fine structure of the tail and midpiece but great variation in the form of the nucleus and particularly the acrosome (Popham, 1979). Sperm morphology has been used successfully as an aid in the examination of the phylogeny, and a knowledge of the ultrastructure of bivalve spermatozoa could be used for taxonomic purposes (Franzen, 1970; Popham, 1979). Previously, regarding reproduction of the pearl oyster, $P$. martensii, there have been some studies on aspects of reproduction, including comparative spermatozoon morphology and bivalve phylogeny (Popham, 1979), and spermiogenesis and ultrastructure of spermatozoa (Kim, 2001), on aspect of habitat and ditribution (Kwon et al., 2003; Min et al., 2004). Even though some works on reproduction, ecology and morphology have been carried out already, there are still gaps in our knowledge on reproductive biology. Little information is available on ultrastructure of spermiogenesis and mature sperm morphology of this species. In particular, taxonomical values of mature sperm morphology of $P$. martensii has not been reported. The acrosome structure of the sperm shows morphological diversity in the bivalve sperm, and hence it may be the most useful structure in assessing phylogenetic relations. Recently, the special substructures in the acrosomal vesicles of the sperm has been used to organize the families in subclasses (Popham, 1979). In association with the acrosomal morphology, Healy (1989) reported that different subclasses of bivalves each have unique acrosomal morphology. Therefore, the acrosomal morphology of the sperm in P.martensii should be compared with the species of other families in subclass Pteriomorphia.

In addition, the number of mitochondria in the sperm midpiece tend to be stable within any given family or superfamily (Healy, 1989, 1995). Therefore, the number of mitochondria in sperm midpiece of this species should be investigated and compared with the same family Pteridae. Beside ultrastructures of germ cells during spermatogenesis, mature sperm morphology should be studied to clarify ultrastructural characteristic in detail.

The present study is the first to describe some taxonomic values of mature sperm morphology and ultrastructure of this species. Therefore, the purpose of the present study is to describe the ultrastructures of germ cells during spermatogenesis and to clarify mature sperm ultrastructural differences by which can be used for taxonomic analysis of this species.

\section{MATERIALS AND METHODS}

\section{Sampling}

For collection specimens, adult Pinctada martensii reared in the tank. The total of 50 male individuals were used for TEM (transmission electron microscope) observations.

\section{Transmission electron microscope observations}

For TEM (transmission electron microscope) observations, excised pieces of the gonads were cut into small pieces and fixed immediately in $2.5 \%$ paraformaldehydeglutaraldehyde in $0.1 \mathrm{M}$ phosphate buffer solution $(\mathrm{pH} 7.4)$ for 2 hours at $4{ }^{\circ} \mathrm{C}$. After prefixation, the specimens were washed several times in the buffer solution and then postfixed in a $1 \%$ osmium tetroxide solution in $0.2 \mathrm{M}$ phosphate buffer $\left(\mathrm{pH}\right.$ 7.4) for 1 hour at $4{ }^{\circ} \mathrm{C}$. Specimens then were dehydrated in increasing concentrations of ethanol, cleared in propylene oxide and embedded in an Epon-Araldite mixture. Ultrathin sections of Epon-embedded specimens were cut with glass knives on a Sorvall MT-2 microtome and LKB ultramicrotome at a thickness of about $80-100 \mathrm{~nm}$. Tissue sections were mounted on collodion-coated copper grids, doubly stained with uranyl acetate followed by lead citrate, and observed with a JEM 100 CX-II (80-KV) electron microscope.

\section{RESULTS}

\section{Germ cell differentiations during spermatogenesis}


The process of spermatogenesis appear to be similar to those of other bivalve species. Spermatogenesis occurs in numerous acini of the testis. The process of spermatogenensis appear to be similar to other bivalves. Spermatogenesis occurs in the acini of the testis can be divided into four stages as follows: (1) spermatogonia, (2) spermatocytes, (3) spermatids and (4) spermatozoa.

Spermatogonia: Spermatogonia contain a large nucleus and mitichondria in the cytoplasm.

Spermatocytes: The spermatogonium develops into the primary spermatocytes by mitotic division. At this stage, two stages of primary and secondary spermatocytes are observed in the acinus wall. Primary spermatocytes are slightly smaller cells (approximately 5.2 to $6.1 \mu \mathrm{m}$ diameter) that are distinguished by nuclei (aprroximately $3.4 \mu \mathrm{m}$ diameter) with more abundant and slightly darkly staining heterochromatin. The nucleus of the primary spermatocyte is similar in size and shape to that of the spermatogonium, however, at this stage the nucleolus is no longer prominent, and the chromatins are distributed in the nucleus. Primary spermatocytes in the stage of first meiotic prophase are distinguished within the germinal layer of the testis, zygotene/patchtene spermatocytes contain nuclei with more highly condensed chromatin and synaptonemal complexes. The synaptonemal complexes in the nucleus appear in the prophase during the first maturation division. cellular outlines are oval in shape (Fig. 1, 2). Primary spermatocytes differentiate into secondary spermatocytes by the meiotic division of primary spermatocytes. At this stage the secondary spermatocytes are rarely observed because of the rapidity of the first meiotic division of the primary spermatocytes. They are irregular in shape and range from about 4.4-5.5 $\mu \mathrm{m}$ in size. Spherical nucleus possess scattered chromatin forming a network. Secondary spermatocytes are frequently observed undergoing meiotic division, and the sizes of secondary spermatocytes become smaller than those of the primary spermatocytes. At this time, several granules, which is originated from the Golgi complex, appear on the nucleus of secondary spermatocyte (Fig. $3)$.

Spermatids: As the testis develops during the testicular development, the secondary spermatocyte develops into the spermatids by the secondary meiotic division. For convenience, spermiogenesis can be divided arbitrarily into two stages: the early and late stages. In the early spermatid stage during spermiogenesis, spermatids (approximately 3.5-4.0 $\mu \mathrm{m}$ diameter) shows oval in shape, and also the nucleus is commonly spherical or oval in shape and occupied the center of the cell. At this stage, nuclei of spermatids (about 2.4-2.6 $\mu \mathrm{m}$ diameter) contain electron-dense heterochromatin materials in the nucleus, and the cytoplasm contains mitochondria (Fig. 4). In the late spermatid stage during spermiogenesis, the morphology of the spermatid nucleus changes gradually during the differentiation of the spermatid, after all, the morphologies of the spermatid nuclei (about $2.0 \mu \mathrm{m}$ diameter) are slightly narrowed. At this time, small granules, which are formed by the Golgi complex in the cytoplasm, migrates to anterior end of the spermatid nucleus, while mitochondria moved to a position just behind the nucleus. At this stage. As shown in Fig. 5, the processes of acrosomal vesicle formation show very complex: a single acrosomal vesicle, which locates at the presumptive anterior pole of the spermatids, is initially oval-shape. At this time, a thick and wide triangular shape as a substructure, which is composed of electron-dense opaque material, appear at $50 \%$ of the acrosomal vesicle which is located at the upper part. However, about $50 \%$ of the acrosomal vesicle which is located at the low part is composed of electron-lucent material. At the same time, the acrosomal vesicle then begins to invaginate on its a nuclear surface, forming the characteristic hollow, conical-shaped acrosome. As differentiations continue, the nuclear surface invaginates to form a digitate, subacrosomal space. At this time, several small mitochondria fuse to form large spherical mitochondria under the posterior nuclear fossa. At the same time a subacrosomal fossa appears as a shallow depression along the apical surface of the nucleus (Fig. 6). 

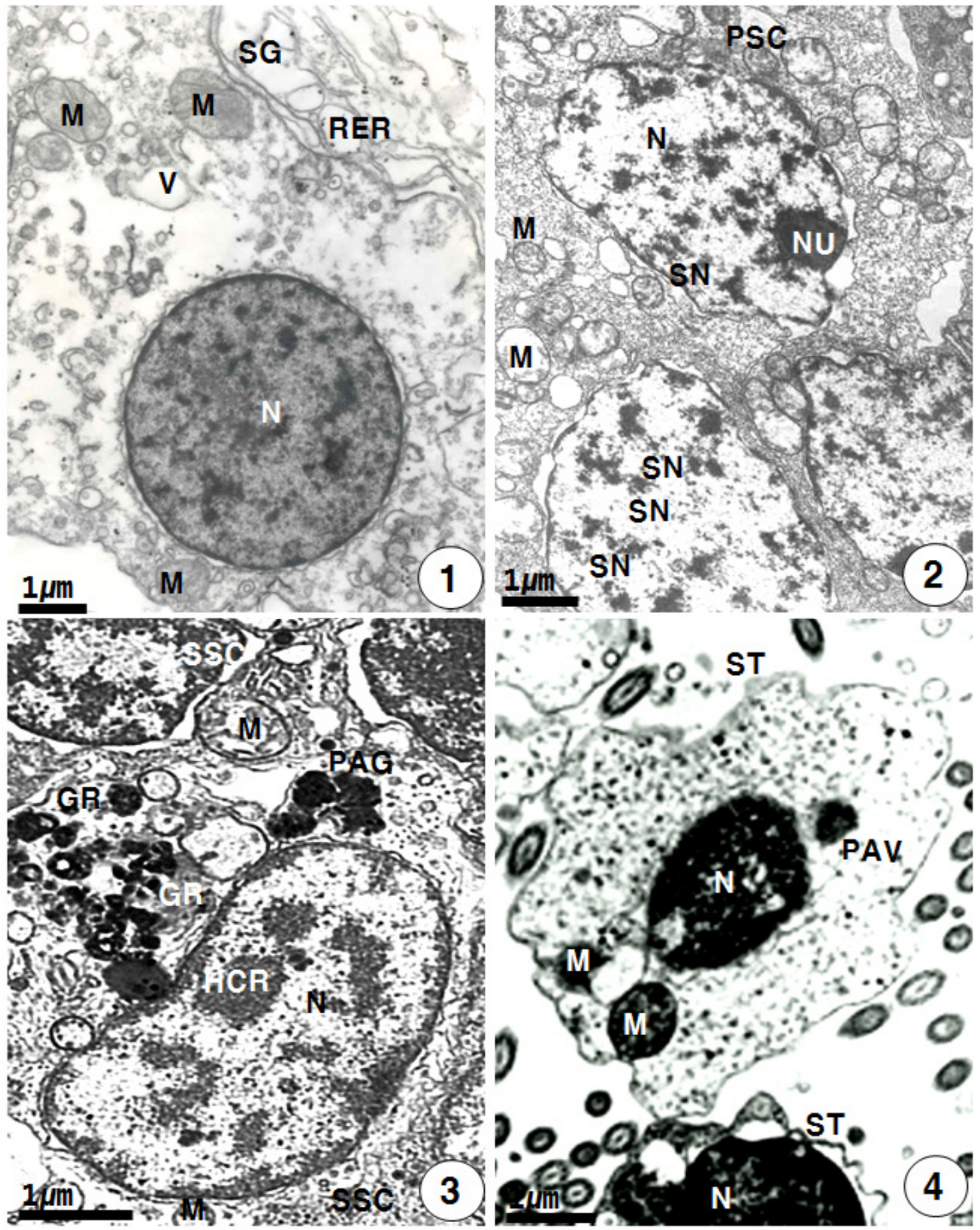

Figs. 1-13. Transmission electron micrographs showing spermatogenesis in male Pinctada martensii. Fig. 1. Spermatogonia (SG). Note chromatins in the nucleus (N) and mitochondria (M) and vacuoles $(\mathrm{V})$ in the cytoplasm. Fig. 2. Primary spermatocyte (PSC). Note several synaptonemal complexes (SN) in the nucleus (N) and a number of mitochondria (M) in the cytoplasm. Fig. 3. Secondary spermatocytes (SSC). Note heterochromatin (HCR) in the nucleus and several granules near proacrosomal granules on the nucleus in the cytoplasm. Fig. 4. A spermatid (ST) and a proacrosomal vesicle. Note heterochromatin (HC) in the nucleus $(\mathrm{N})$, mitochondria $(\mathrm{M})$ and a proacrosomal vesicle near the nucleus. 

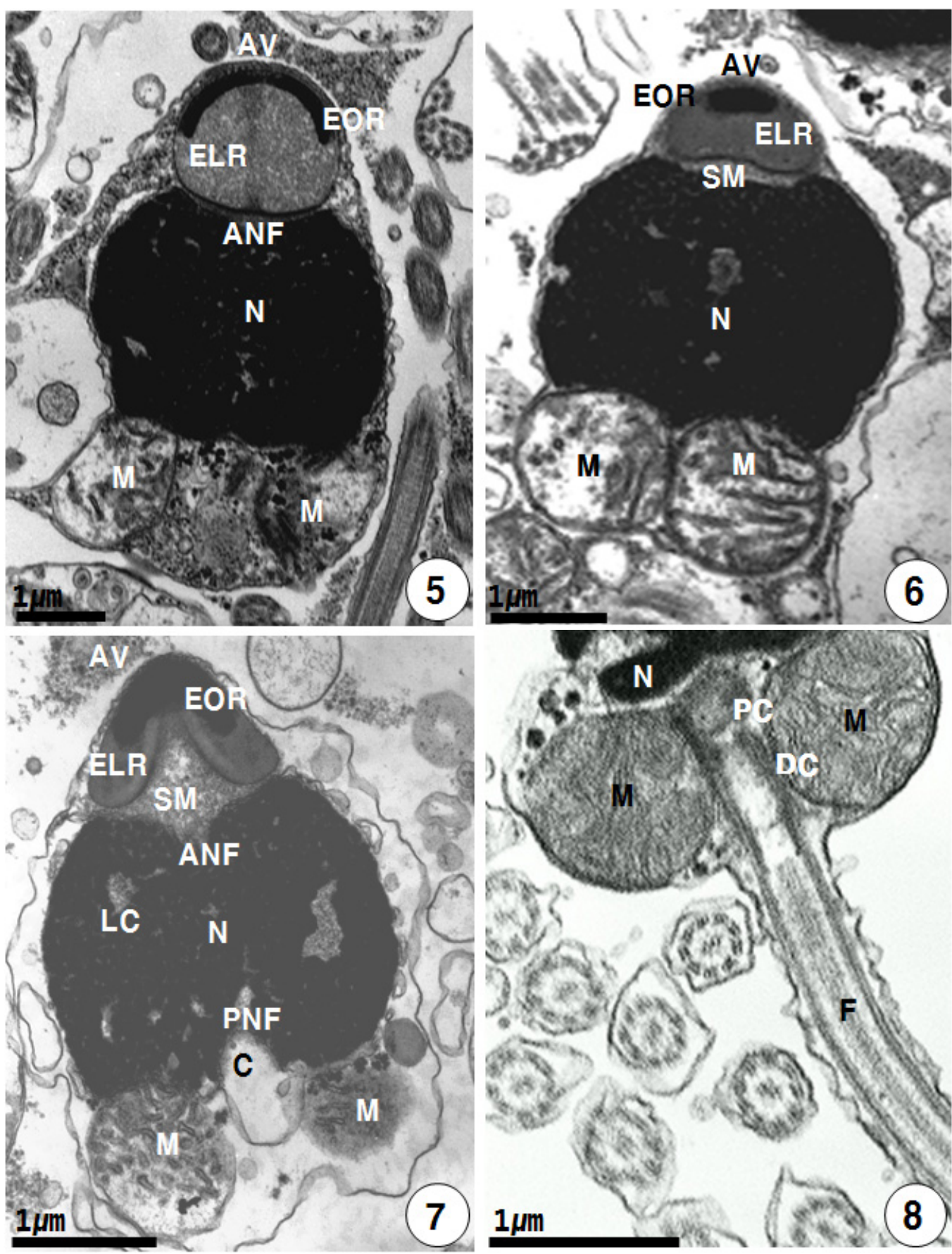

Fig. 5. A spermatid (ST) during acrosomal vesicle formation. Note the appearances of an electron opaque region and an electron-lucent region in the acrosomal vesicle (AV) and anterior nuclear fossa (ANF) of the nucleus (N) with spherical mitochondria (M). Fig. 6. Spermatid during acrosome formation. Note variation of an acrosomal vesicle containing electron opaque region (EQR) and electron-lucent region (ELR), and subacrosomal material near the nucleus and mitochondria. Fig. 7. Late stage of a spermatid during acrosome formation. Note electron opaque region (EOR) and electron lucent region (ELR) in the acrosomal vesicle (AV), subacrosomal material (SM) in the space between the acrosomal vesicle (AV) and anterior nuclear fossa (ANF), lacunae (LC) in the nucleus (N) near the posterior nuclear fossa and centriole. Fig. 8. The same stage of a spermatid during spermiogenesis. Note sperm midpiece containing a part of the nucleus $(\mathrm{N})$, a proximal $(\mathrm{PC})$ and distal centrioles $(\mathrm{DC})$ and a flagellum $(\mathrm{F})$. 
As shown in Fig. 7, two components (the ultrastructure of the acrosomal vesicle and deposit of subacrosomal materials) of the acrosomal vesicle are easily recognized during the acrosomal formation. The acrosomal vesicle then begins to invaginate on its a nuclear surface, forming the characteristic hollow, conical-shaped acrosome. Finally, the morphology of the acrosomal vesicle becomes the cone-shape by way of various morphological changes and the course of invagination from initial oval shape.

At this stage during spermiogenesis, the acrosomal vesicle of the late spermatid is composed of two kinds of obviously different regions (parts): The outer part (region) of the acrosomal vesicle is formed by a thick triangular shape line (region) being composed of electron-dense opaque material which is occupied $50 \%$ of the upper part of the acrosomal vesicle, while the inner part (region) of the lower part of the acrosomal vesicle is composed of the electron-lucent material.

At this time, the acrosomal vesicle (about $0.60 \mu$ $\mathrm{m}$ long) is occupied by subacrosomal material which comprises embedded in a coasely granular matrix, and forms membrane bound. However, the axial rod is not present in the subacrosomal material in the anteriorly invaginated subacrosomal space of the acrosomal vesicle.

During the late stage of the spermatid, the granular nucleus becomes smaller (approximately 1.25 $\mu \mathrm{m}$ long), and the nuclear contents continue to condense, there is continued loss of cytoplasm by sloughing. At the same time, in the midpiece of spermatozoa, mitochondria become reduced in number but increase in size. The larger mitochondria form a close association with the nucleus. As further development occurs, the mitochondria come to occupy the end of the cell opposite to the acrosome, thus forming the sperm midpiece. The spermatid middlepiece contains the distal centriole and an adjacent proximal centriole which lies next to the posterior nuclear envelope at a $90^{\circ}$ angle to the long axis of the cell. At the same time, the tail appears during the late spermatid stage, developing from the distal centriole; the proximal centriole occupies a position between the distal centriole and the nucleus. However, two lateral satellite fibers are not found near the distal centriole (Fig. 8).

Spermatozoa: An acrosomal vesicle, which is occupied about $50 \%$ of the upper part of the acrosomal vesicle contains high electron dense opaque material. In particular, the apex part and the half (the upper parts) of right and left lateral basal rings of an acrosomal vesicle show electron opaque regions, as seen in subclass Pteriomorphia species.

Mature spermatozoa of this species is approximately 47-50 $\mu \mathrm{m}$, and consist of conical acrosome positioned at the top of an oval nucleus, a pair of centrioles surrounded by four or five spherical mitochondria, and a flagellum (Fig. 9). An acrosome on the nucleus is composed of an acrosomal vesicle (about $0.60 \mu \mathrm{m}$ long) and a granular subacrosomal material exist in a coasely granular matrix. At this stage, the acrosomal vesicle, which is formed by two kinds of electron-dense materials, appears from the half of right and left lateral basal rings of the acrosomal vesicle to the apex part of the acrosomal vesicle: in particular, a thick triangular-shape substructure, which is composed of the electron-dense opaque material, appears along the upper part (50\% of total area) of the acrosomal vesicle, while the lower part (50\% of total area) is composed of the electron-dense lucent material in the acrosomal vesicle from the base to the half region (the central region) of the acrosomal vesicle. The central hollow of the acrosome contains a granular subacrosomal material. However, the axial rod do not exist in the granular subacrosomal material. The acrosomal vesicle is somewhat deeply invaginated. The invagination is narrow anteriorly, as seen in subclass Pteriomorphia species.

The shape of the nucleus $(1.24 \mu \mathrm{m})$ is a short and oval-shaped. In particular, irregular electron-lucent lacunae are present in the nucleus. And also a short, shallow basal invagination appears in the nucleus. The sperm miedpiece includes four or five spherical mitochondria with well-developed cristae and the proxiamal and distal centrioles (Figs. 11, 12).

The proximal centriole lies at $90^{\circ}$ to the distal 

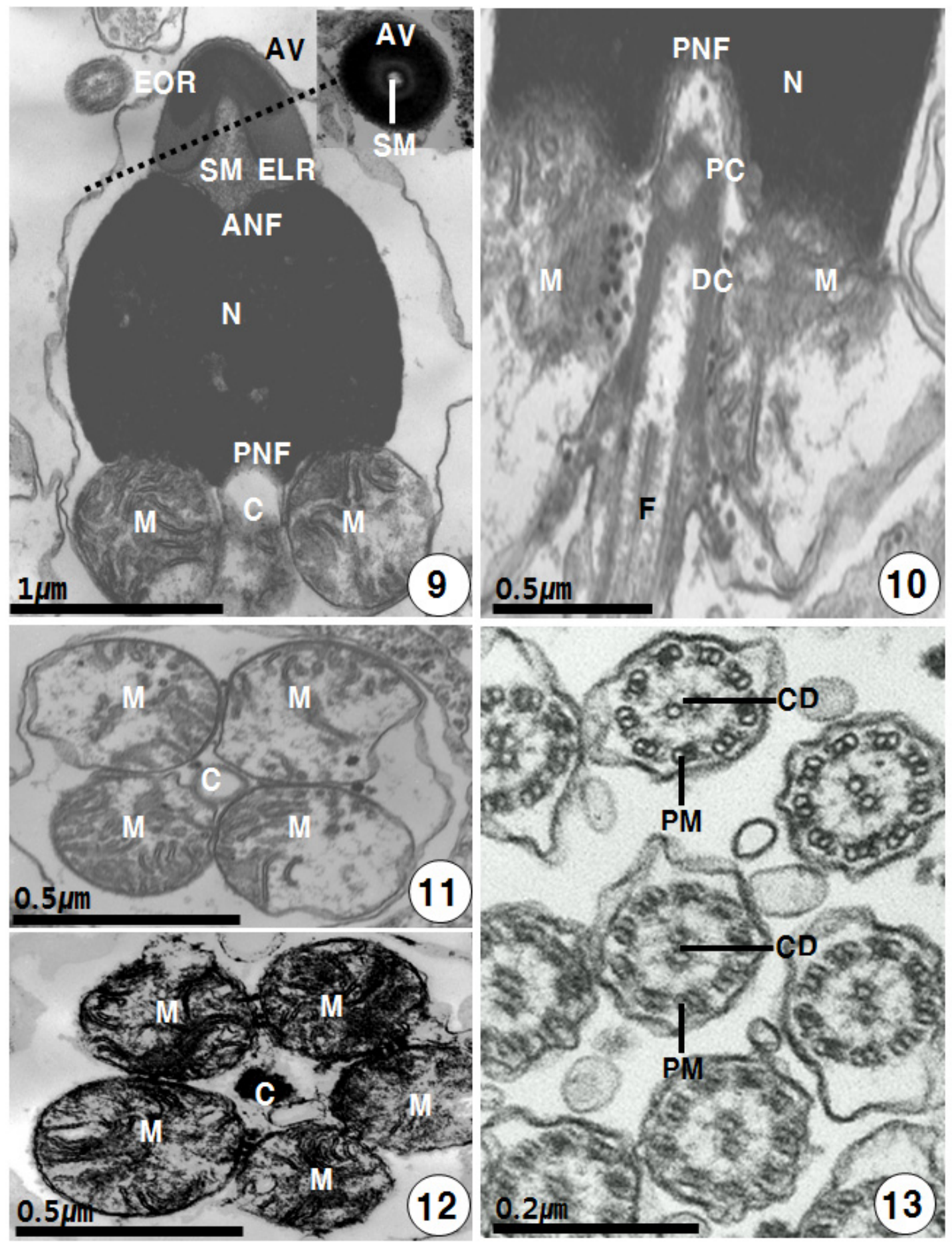

Fig. 9. A completed spermatozoon containing an acrosome, the nucleus, sperm midpiece. Note electron opaque region and electron lucent region in the acrosomal vesicle (AV), the nucleus $(\mathrm{N})$ and sperm midpiece with mitochondria (M). Fig. 10. The sperm midpiece of a completed sperm. Note a proximal (PC) and distal centriole (DC) surrounded with mitochondria (M) beneath the posterior nuclear fossa (PNF). Figs. 11 and 12. Sperm midpiece of completed sperms. Note 4 or 5 mitochondria surrounding centrioles in the sperm midpiece. Fig. 13. Cross sectioned spermatozoa. Note an axoneme showing 9+2 structure containing 9 pairs of peripheral microtubules (PM) and a pair of central doublets (CD). 
centriole and sperm longitudinal axis, and is connected to a shallow invagination of the nucleus by a thin layer of dense material. The distal centriole is attached to the plasma membrane, and its continuous with the flagellum (Fig. 10). However, satellite fibers are not found near the distal centriole. The flagellum is about 45-48 $\mu \mathrm{m}$ long, and exhibits a classic $9+2$ microtubular substructure axoneme (that is, nine peripheral microtubules surrounding a central doublets) (Fig. 13). The flagellum, which is originates from the distal centriole, is surrounded at its base by plasma membrane.

\section{Discussion}

The general process of spermatogenesis in $P$. martensii similar to that of the other bivalves and more specifically of other Pteriormorphia species (Gaulejac et al., 1995; Kim et al., 2010a). Numerous studies have shown that all bivalves have primitive spermatozoa (Franzén, 1983), typical of animals which release their gametes into the surrounding water (Gaulejac et al., 1995). Spermatogenesis of $P$. martensii shows some similar phenomena to those of other bivalves (Eckelbarger et al., 1990; Chung et al., 2007; Kim et al., 2010b). Recently, Sousa et al., (1989) suggested that the Golgi complex may form only a single acrosomal vesicle in a manner similar to other molluscs. As seen in the spermatid stage in Perna perna (Bernard and Hodgson, 1985) and Pecten maximus (Dorange and Le Pennec, 1989).

In this study, in case of $P$ martensii, the proacrosomal granule appeared near the Golgi complex in synthetic activity during the early developmental stage of spermatids. At this time, several small electron-dense granules are also observed in the vicinity of proacrosomal granule (Figs. $3,4)$. It is probable that the small granules, which are produced by the Golgi complex, fused to form a single proacrosomal vesicle as seen in externally-fertilizing bivalves in other bivalves. (Bernard and Hodgson, 1985; Hodgson and Bernard, 1986).

In this study, a substructure showing a thick and wide triangular shape in the acrosomal vesicle of $P$. martensii appears in the anterior side of the spermatid. About 50\% of the upper part (from the half region to the apex region) of the acrosomal vesicle is composed of the outer electron opaque region, while about $50 \%$ of the inner part (from the half region to the basal region) of the acrosomal vesicle is composed of electron lucent region. Such similar differentiation has been recorded in the acrosome of other family (Popham, 1979; Bernard and Hodgson, 1985). These regions of differing electron opacity provably reflect the differing functions of the acrosome during the process of fertilization (Hodgen and Bernard., 1986).

To date, the modes of acrosmal developments and formations in bivalves and gastropods associated with external or internal fertilizations have been studied by many researchers (Longo and Dornfeld, 1967; Longo and Anderson, 1969; Baccetti and Afzelius, 1976; Bacetti, 1979; Bernard and Hodgson, 1985; Healy, 1989). Healy (1989) reported that acrosomal development in the Mollusca can be classified into three modes: The first mode of the acrosomeal development is observed in numerous other externally-fertilizing bivalves and other invertebrate. several electron-dense proacrosomal vesicles, which are at first formed by the Golgi complex, become later the definitive acrosomal vesicle by the fusion of several Golgi-derived vesicles. this pattern mentioned above belongs to the first mode of the acrosomeal development.

The second mode of acrosomal development is observed in internally fertilizing molluscs (higher prosobranch gastropods, opisthobranch and pulmonate gastropods) and in many other internally fertilizing animal groups. The initial definitive acrosomal vesicle is formed by the Golgi complex of a large receptacle vesicle, and then the growth of which is achieved through fusion of small vesicles budded from the Golgi cisternae, or from materials channeled directly from the cisternae. This pattern belongs to the second mode of the acrosomeal development.

The third mode of acrosomal development could be viewed as a variation on the first mode of acrosomal development. In case of the freshwater clam Neotrigonia (Unionoidea), acrosome formation is 
formed through production of multiple proacrosomal vesicles which do not fuse into a single acrosomal vesicle. Therefore, this pattern could be viewed as a variation on the first mode of acrosomal development. In this study, in the early stage of the spermatid during spermiogenesis, a few electron-dense granules, which are at first formed by the Golgi complex, became later the definitive acrosomal vesicle by the fusion of small proacrosomal granules. Therefore, of three modes of acrosomal development and formation, the processes of acrosomal development and formation of $P$. martensii belongs to the first mode (Figs. 3, 4).

In this study, morphologies and sizes of the sperm acrosomes in Pteriidae species showed similar morphological and ultrastructural characteristics, as seen in other family species. In general, the acrosome could be classified into five shapes: cone, long cone, modified cone, cap, modified cap shapes. In this study, the acrosomal morphology of the spermatozoon of this species was a cone shape. however, and also, of the species of Veneridae in subclass Heterodonta, $C$. sinensis and Phacosoma japonicus were the cone shape, unlike Saxidomus japonicus, Meretrix lusoria, Notochione jedoensis showed the cap shape (Kim, 2001). In contrast several species of Mytilidae (Longo and Dornfeld, 1967; Bernard and Hodgson, 1985) and Ostreidae (Kim, 2001), this absence of an axial rod in the acrosome may be correlated with the thickness of the oocyte vitelline envelope (Galangau, 1969). Popham (1979) stated that the absence of an axial rod in the acrosome represents the primitive bivalve condition. Healy (1995) reported that of sperm ultrastructures of bivalves, the number of mitochondria in the sperm midpiece are now widely used in taxonomic analyses. That is the reason that the number of mitochondria in the sperm midpiece tends to be stable within any given family or superfamily (Healy, 1989, 1995). Recently, some authors (Chung and Ryou, 2000; Kim, 2001; Chung et al., 2007, 2010) described that the number of mitochondria at the midpiece of the spermatozoon were five in Pinnidae Arcidae, Mytilidae, and Pteriidae in subclass Pteriomorphia, In this study, we found that there are five mitochondria in the midpiece. Therefore, the number of mitochondria in the sperm midpiece were not concerned with the subclasses, however, their numbers were concerned with family or superfamily (Healy, 1995). Therefore, our results on the number of mitochondria coincide with opinions of Healy (1995).

\section{ACKNOWLEDGMENT}

The authors are grateful to Prof. Emeritus, Ee-Yung Chung of Kunsan National University for helpful comments on the manuscript. Thanks are also to two reviews for helpful comments.

\section{REFERENCES}

Baccetti, B, and Afzelius, B. A. (1976) Biology of sperm cell. S. Krager, New York p. 1-254 (Monogr Devel Biol No. 10).

Baccetti, B. (1979) The evolution of the acrosomal complex. In: Fawcett DW., Bedford JM (eds.) The spermatozoon. Urban Schwarzenberg, Baltimore p. 305-328

Bernard, R. T. F, and Hodgson. AN (1985) The fine structure of the sperm and spermatid differentiation in the brown mussel Pernaperna. South Africa Journal of Zoology, 20:5-9.

Chung, E. Y. and Ryou, D. K. (2000) Gametogenesis and sexual maturation of the surf clam, Mactra veneriformis on the west coast of Korea. Malacologia, 42: 149-163.

Chung, E. Y., Chung, C. H., Kim, J. H., Park, S. W. and Park, K. H. (2010) Ultrastructuresof germ cells and the accessory cells during spermatogenesis in male Gomphina veneriformis (Bivalvia: Veneridae) on the east coast of Korea. Korean Journal of Malacology, 26: 51-62.

Chung, E. Y.,, Kim, E. J. and Park, G.M. (2007) Spermatogenesis and sexual maturation in male Mactra chinensis (Bivalvia: Mactridae) of Korea. Integrative Bioscience, 11: 227-234.

Dorange G. and Le Pennec M. (1989) Ultrastructural characteristics of spermatogenesis in Pecten maximus (Mollusca, Bivalvia). Invertebrate Reproduction \& Development, 15: 109-117.

Eckelbarger K. J, Bieler R. and Mikkelsen P. M. (1990) ltrastructure of sperm development and mature sperm morphology in three species of commensal bivalves (Mollusca: Galeommatoidea). Journal of Morphology, 205: 63-75.

Eckelbarger K. J. and Davis C. V. (1996) Ultrastructure of the gonad and gametogenesis in the eastern oyster, Crassostrea virginica. II. Testis and spermatogenesis. Marine Biology, 127: 89-96.

Franzén A. (1970) Phylogenetic aspects of the 
mophology spermatozoa and spermiogenesis in Baccetti B (ed): "Comparative spermatology". Accademia Nationale Dei Lincei, Rome 573pp.

Franzén, $\AA$. (1983) Ultrastructural studies of spermatozoa in three bivalve species with notes on evolution of elongated sperm nucleus in primitive spermatozoa. Gamete Research 7: 199-214.

Franzen, A. (1956) On spermiogenesis. Morphology of the spermatozoon and biology of fertilization among invertebrates. Zool. Bidr. Upps,. 31: 255-482.

Galangau, M. V. (1969) Etude en microscopie eletronique de la gametodenese de Milax gagates (Draparnaud, 1801) (Gasteropodes, Pulmones, Limacidae). Evolution des ultrastructures au cours de la spermatodenese chez dirrerents types de mollusques, These Doct. Etat. Montepellier, P. 151.

Gaulejac, de J., Jenry, M. and Vicente N. (1995) An ultrastructural study of gametogenesis of the marine bivalve Pinna nobilis (Linnaeus, 1758). II. Spermatogenesis. Journal of Molluscan Study, 61: 393-403.

Healy, J. M. (1989) Spermiogenesis and spermatozoa in the relict bivalve genus Neotrigonia: relevance to trigonioid relationships, particularly Unionoidea. Marine Biology, 103: 75-85.

Healy, J. M. (1995) Sperm ultrastructure in in the marine bivalve families Carditidae and Crassatellidae and its bearing on unification of the Crasssatelloidea with the Carditoidea. Zoological Science, 24: 21-28.

Hodgson, A. N. and Bernard, R. T. F. (1986) Ultrastructure of the sperm and spermatogenesis of three species of Mytilidae (Mollusca, Bivalvia). Gamete Research, 15: 123-135.

Jamieson, B. G. M. (1991) Fish evolution and systematics: evidence from spermatozoa. Cambridge University Press, Cambridge. pp.181-194.

Kim, J. .H., Chung, E. Y., Choi, K. H, Lee, K. Y, and Choi, M. S. (2010a) Ultrastructure of the testis and germ cell development during spermatogenesis in male Crassostrea gigas (Bivalvia: Ostreidae) in western Korea. Korean Journal Malacology, 26: 235-244.
Kim, J. H. (2001) Spermatogenesis and comparative ultrastructure of spermatozoa in several species of Korean economic bivalves (13 families, 34 species). Ph.D. thesis, Pukyung National University 161pp.

Kim, J. H. and Kim, S. H. (2011) Spermiogenesis and Taxonomic Value of Sperm Morphologies of Two Species in Veneridae (Bivalvia: Heterodonta). Korean J. Marlacol. 27(2): 149-157.

Kim, J. H., Chung E. Y, Choi K. H, Park K. H, Park S. W. (2010b) Ultrastructure of germ cells during spermatogenesis and some characteristics of sperm morphology in male Mytilus coruscus (Bivalvia: Mitilidae) on the west coast of Korea. Korean Journal of Malacology, 26: 33-43.

Kwon, O. K., Park G. M. and Lee, J. S. (2003) Coloured shells of Korea. Academy Pubshing Co. Seoul, 288pp.

Longo, F. J. and Anderson, E. (1969) Spermatogenesis in the surf clam Spisular solidissima with special reference to the formation of the acrosomal vesicle. Journal of Ultrastructure Research, 27: 435-443.

Longo, F. J. and Dornfeld, E. J. (1967) The fine structure of spermatid differentiation in the mussel Mytilus edulis. J. Ultrastruct. Res., 20: $462-480$

Min, D. K. Lee, J. S., Ko, D. B. and Je, J. G. (2004) Mollusks in Korea. Hanguel Graphics, Busan, Korea $566 \mathrm{pp}$

Popham J. D. (1979) Comparative spermatozoon morphology and bivalve phylogeny. Malacological Review, 12: 1-20.

Popham, J. D. (1974) Comparative morphometrics of the acrosomes of the sperms of externally and internally fertilizing sperms of the sperms of the shipworms (Teredinidae, Bivalvia, Mollusca). Cell Tissue Research, 150: 291-297.

Sousa, M., Corral, L. and Azevedo, C. (1989) Ultrastructural and cytochemical study of spermatogenesis in Scrobicula riaplana (Mollusca, Bivalvia). Gamete Research, 24: 393-401. 